\title{
Antibiotics against Pseudomonas aeruginosa for COPD exacerbation in ICU: a I0-year retrospective study
}

This article was published in the following Dove Press journal:

International Journal of COPD

17 February 2015

Number of times this article has been viewed

\author{
Benjamin Planquette ${ }^{1-4}$ \\ Julien Péron ${ }^{2}$ \\ Etienne Dubuisson' \\ Ariane Roujansky' \\ Virginie Laurent' \\ Alban Le Monnier ${ }^{3}$ \\ Stephane Legriel' \\ Alexis Ferre ${ }^{4}$ \\ Fabrice Bruneel' \\ Peter G Chiles ${ }^{5}$ \\ Jean P Bedos'
}

'Réanimation Polyvalente, Centre Hospitalier de Versailles, Le Chesnay, France; ${ }^{2}$ Unité de Biostatistique Médicale, Hôpital Lyon Sud, Lyon, France; ${ }^{3}$ Service de Microbiologie, Centre Hospitalier de Versailles, Le Chesnay, France; ${ }^{4}$ Service de Pneumologie et de Soins Intensifs, Hôpital Européen Georges Pompidou, Université Paris René Descartes, Paris, France; ${ }^{5}$ Division of Pulmonary and Critical Care Medicine, University of California, San Diego, La Jolla, CA, USA
Correspondence: Benjamin Planquette Réanimation Polyvalente, Centre Hospitalier de Versailles, 177 rue de Versailles, 78150 Le Chesnay, France $\mathrm{Tel}+33$ । 39638700

Fax +33 | 39638688

Email benjamin.planquette@gmail.com
Summary: Chronic obstructive pulmonary disease (COPD) is a frequent source of hospitalization. Antibiotics are largely prescribed during COPD exacerbation. Our hypothesis is that large broad-spectrum antibiotics are more and more frequently prescribed. Our results confirm this trend and highlight that the increase in large broad-spectrum use in COPD exacerbation is largely unexplained.

Background: Acute COPD exacerbation (AECOPD) is frequently due to respiratory tract infection, and the benefit of antipseudomonal antibiotics (APA) is still debated. Health careassociated pneumonia (HCAP) was defined in 2005 and requires broad-spectrum antibiotherapy. The main objectives are to describe the antibiotic use for AECOPD in intensive care unit and to identify factors associated with APA use and AECOPD prognosis.

Methods: We conducted a monocentric, retrospective study on all AECOPDs in the intensive care unit treated by antibiotics for respiratory tract infection. Treatment failure (TF) was defined by death, secondary need for mechanical ventilation, or secondary systemic steroid treatment. A multivariate analysis was used to assess factors associated with APA prescription and TF. Results: From January 2000 to December 2011, 111 patients were included. Mean age was 69 years $( \pm 12)$, mean forced expiratory volume $38 \%$ of theoretic value $( \pm 13)$. Thirty-five $(31 \%)$ patients were intubated, and $52(47 \%)$ were treated with noninvasive ventilation. From 107 patients, 8 (7\%) cases of Pseudomonas aeruginosa were documented. APAs were prescribed in $21 \%$ of patients before 2006 versus $57 \%$ after $(P=0.001)$. TF prevalence was $31 \%$. Risk factors for P. aeruginosa in COPD and HCAP diagnosis did not influence APA, whereas the post-2006 period was independently associated with APA prescription (odds ratio 6.2; 95\% confidence interval 1.9-20.3; $P=0.0013$ ). APA did not improve TF (odds ratio $1.09 ; 95 \%$ confidence interval 0.37-3.2).

Conclusion: HCAP guidelines were followed by an increase in APA use in AECOPD, without an improvement in prognosis. HCAP prevalence cannot account for the increasing APA trend. Time effect reveals a drift in practices. The microbiological effect of such a drift must be evaluated.

Keywords: COPD, exacerbation, Pseudomonas aeurginosa, antibiotics, ICU

\section{Introduction}

Chronic obstructive pulmonary disease (COPD) is a leading cause of mortality worldwide and is associated with an important morbidity ${ }^{1,2}$ related in large part to acute COPD exacerbations (AECOPD). Recently, AECOPD has been identified as a prognostic factor $^{3,4}$ and is associated with a reduction in quality of life and lung function. ${ }^{5}$ The large majority of AECOPD may be triggered by respiratory tract acute viral or bacterial infections. ${ }^{6,7}$ Even if the role of bacterial pathogens remains controversial in the 
physiopathology of exacerbations, the last GOLD guidelines suggested initiating antibiotics in case of AECOPD. ${ }^{8}$

COPD patients are more likely to be colonized or infected by Pseudomonas aeruginosa (PA) that is isolated from 4\% to $15 \%$ of COPD sputum samples ${ }^{6,7,9,10}$ A meta-analysis showed that PA could trigger AECOPD. The acquisition of a new strain of PA seems to be associated with AECOPD. ${ }^{11}$ PA colonization risk factors have been described. ${ }^{12,13}$ In this sense, a prediction model has been developed and included forced expiratory volume (FEV) $<35 \%$ of the predicted value, systemic steroid use, and prior antibiotic therapy (within the preceding 3 months). When the three criteria were absent, PA involvement in AECOPD could be excluded with a negative predictive value of $89 \%$.

Health care-associated pneumonia (HCAP) was defined in $2005^{14}$ and concerns patients at risk for sepsis caused by potential multidrug-resistant bacteria, especially PA. Amercian Thoracic Society (ATS) guidelines ${ }^{15}$ suggested treating HCAP patients with large-spectrum antibiotics. A recent publication ${ }^{16}$ suggested that multi drug resistant (MDR) bacteria are common in AECOPD. Patients admitted in the intensive care unit (ICU) for an AECOPD are frequently considered as having a health care respiratory infection.

The main objectives of the present study are (1) to describe the antibiotics used in AECOPD patients admitted in the ICU and (2) to analyze factors associated with the use of antibiotics active against PA and their impact on AECOPD prognosis.

\section{Materials and methods}

The present study is a monocentric (Centre Hospitalier de Versailles, Site Mignot, Le Chesnay, France) retrospective study conducted from January 2000 to December 2010. The study design was approved by the ethics committee of the Société de Réanimation de Langue Française (CE SRLF 12-392), and the data file was declared to the Commission Nationale de l'Informatique et des Libertés (No déclaration CNIL: 1631499 v 0).

\section{Patients}

We reviewed the charts of all consecutive patients who met five inclusion criteria: (1) age older than 18 years, (2) admitted in the ICU, (3) acute exacerbation of COPD, (4) lower respiratory tract infection (bronchitis or pneumonia) at the time of admission in ICU, and (5) initial probabilistic antibiotherapy initiated at ICU admission.
Patients were excluded from the study if they had one or more of the following criteria: (1) cystic fibrosis, (2) immunocompromised status (defined by HIV status, aplasia, or anti-tumor necrosis factor treatment), and (3) an indication for antibiotics different than lower tract infection.

\section{Definitions}

Pneumonia was defined as symptoms and signs consistent with lower respiratory tract infection, new lung infiltrate by radiography or computed tomography.

HCAP was defined in the patients with clinical and radiological pneumonia who met any one of the following criteria: recent hospitalization for at least 48 hours during the preceding 90 days, admission from a longterm care facility, receipt of hemodialysis or wound care, and/or recent intravenous treatment (within the previous 30 days) with broad-spectrum antimicrobials. Pneumonia was considered as nosocomial if diagnosed after 2 days of hospitalization; ventilator-acquired pneumonia (VAP) was not considered in the present study. In the other cases, pneumonia was considered as a community-acquired pneumonia.

The following antibiotics are defined as the group of antibiotics that are active against PA (antipseudomonal antibiotics [APA]): piperacillin, piperacillin-tazobactam, ceftazidime, cefepime, imipenem or other carbapenems, ciprofloxacin, amikacin, tobramycin, and gentamycin. Amoxicillin, amoxicillin-clavulanate, cefotaxime, ceftriaxone, levofoloxacin, moxifloxacin, and spiramycin are antibiotics inactive against PA (AIPA) and defined the AIPA group. All these antibiotics defined the group of AIPA. Antibiotics were adapted if they were modified to reduce the initial spectrum and/or if an APA was changed for an AIPA.

\section{Endpoint}

Two periods were compared: period 1 (before HCAP and ATS 2005 guidelines) from January 2000 to December 2005 and period 2 (after HCAP and ATS 2005 guidelines) from January 2006 to December 2010.

Following the protocol used in the MAESTRAL study, ${ }^{17}$ treatment failure (TF) was a composite endpoint showing the requirement for additional or alternate treatment for the AECOPD defined by: (1) in ICU death, (2) an increase in the mechanical ventilator support after day 2 (initiation of noninvasive ventilation [NIV] and necessity of intubation in a patient with NIV), or (3) initiation of oral steroid after day 2 . 


\section{Data collection}

Data were retrospectively extracted from the medical and nurses files. Demographic data included age, sex, and body mass index. Associated comorbidity factors were defined as diabetes mellitus, congestive heart failure (using the ventricular ejection fraction measured by ultrasound, cut-off $1<40 \%$ ), and hypertension requiring treatment. COPD status and treatment were investigated using the following data: smoking status (cumulative smoking [packs per year] and active smoker status), lung function determined by FEV (absolute value in milliliters and ratio to the predicted value expressed in percentage), previous known airways PA colonization, and chronic oral steroid treatment ( $>5 \mathrm{mg} /$ day).

Results from biological tests at ICU admission were also collected: hemoglobin ( $\mathrm{g} / \mathrm{dL})$, leucocytes count, serum creatinine level, serum protein level, and arterial blood gas analysis. Severity of illness was evaluated on the first ICU day using the simplified acute physiology score (SAPS II).

AECOPD treatments were recorded: NIV or invasive mechanical ventilation and use of systemic corticosteroid. All antibiotics received at admission and during ICU stay were recorded and classified according to their activity against PA (APA or AIPA). All respiratory samples at ICU admission (sputum, tracheal aspirate, or distal protected sample) were recorded. If PA was documented, the antibiotic susceptibility profile was specifically requested from the microbiological laboratory. Nosocomial events and their antibiotic treatments were also recorded, as well as length of stay and in-ICU deaths.

\section{Statistical analysis}

Proportions were calculated for categorical data, whereas median and interquartile ranges were calculated for continuous data. Statistical significance for categorical data was assessed using a $\chi^{2}$ test or a Fisher's test, as appropriate. Continuous variables were compared using the Mann-Whitney $U$-test.

Univariate and multivariable linear regression analyses were used to identify factors associated with APA. The following patient characteristics were investigated: period of admission, sex, age, body mass index, comorbidities, FEV, oral steroid at admission, PA in respiratory sample, health care-associated infection, SAPS II (Simplified Acute Physiology Score II), and ventilation at ICU admission. Then, univariate and multivariate analyses were used to identify factors associated with poor outcomes. Covariates included in models were age, FEV, oral steroids at admission, body mass index, APA, PA in respiratory sample, bacterial colonization, health care-associated infection, IGS, and ventilation at ICU admission. Both multivariable models included all the abovementioned covariates. No covariate selection was performed because it was deemed desirable to include as many factors associated with APA prescription or poor outcomes as possible. Covariates were considered statistically associated with APA prescription or poor outcomes if the associated $P$-value was $<0.05$. A multivariate logistic regression was used to assess the factors associated with the prescription of APA and with poor outcome. Odds ratio and their $95 \%$ confidence intervals were calculated. All factors of interest and potential confounding factors were included in the multivariate models. Continuous variables were assessed for linearity, and nonlinear covariates were categorized using the most relevant cut point. The added value of each covariate was evaluated using a likelihood ratio test. Statistical significance was set a priori at $\alpha \leq 0.05$ (two-tailed). All statistical analyses were performed using " $R$ " statistical software (version 2.14.1; http://www.R-project.org/).

\section{Results Population characteristics}

Two hundred twenty-three consecutive patients were admitted in our ICU for AECOPD during the study period. One hundred and twelve patients did not meet the inclusion criteria and were not included in the present analysis.

The 111 remaining patients constituted the population of interest (Figure 1). There were 76 men (68\%) and 35 women; the median age was 72 years. Table 1 shows the main demographic and functional characteristics of the study population on the day of ICU admission. Spirometry was available for $75 \%$ of patients, and the mean FEV was $38 \% \pm 13 \%$. Fifty patients did not present any PA risk factors, 30 patients received chronic corticosteroids before ICU admission, and only 34 patients (13.5\%) had two or more risk factors for PA colonization. Eighty-seven patients received mechanical ventilation at ICU admission: 35 (31\%) were intubated, whereas $52(47 \%)$ received NIV. Among these 52 patients under NIV, 10 were intubated. Causes of AECOPD were as follows: 22 acute bronchitis (20\%), 66 community-acquired pneumonia (59\%), 9 HCAP (8\%), and 9 nosocomial pneumonia (13\%). The median duration of ICU stay was 7 days (interquartile 25-75 [4-18]).

Table 2 shows the demographic characteristics of patients who were hospitalized during the said period. No difference was found. Figure 2 presents AECOPD causes among the period. 


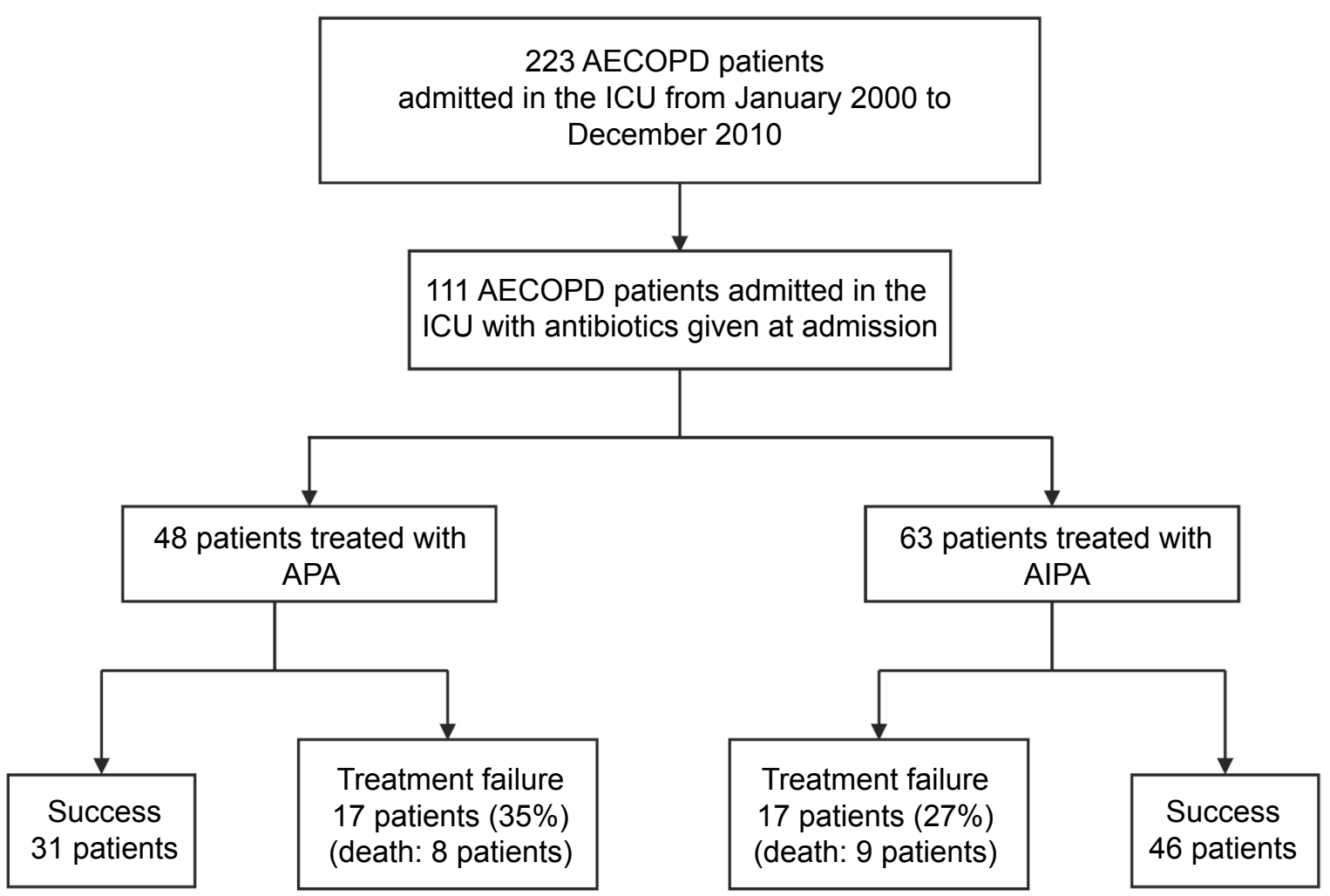

Figure I Study flow chart.

Abbreviations: AECOPD, acute chronic obstructive pulmonary disease exacerbation; AIPA, antibiotics inactive against Pseudomonas aeruginosa; APA, antipseudomonal antibiotics; ICU, intensive care unit.

A large majority of patients $(\mathrm{n}=107,97 \%)$ had a respiratory sample. Among, the 53 positive samples, only eight PA were isolated in eight patients. Six antibiotic sensitivity patterns were documented: all presented a natural antibiotic susceptibility strain. Table 3 presents the main characteristics of the eight patients with a PA-positive respiratory sample.

\section{Antibiotics use in AECOPD}

Forty-eight patients (43\%) were treated with an APA during the study period. Table 2 presents the pattern of prescription of APA among the period. Figure 2 shows the APA use rising up from $22 \%$ before 2006 to $60.7 \%$ after $2006(P<0.001)$. Figure 3 presents the proportion of APA use among the two periods for each diagnosis of lower respiratory tract infection done at the time of ICU admission. The increase in APA use concerns all kinds of diagnoses. APA treatments were modified in 24 patients (50\%).

\section{Factors associated with APA prescription}

The multivariable regression model subsequently revealed that initial invasive mechanical ventilation $(P=0.003)$ and period 2 (from January 2006 to December 2012) $(P=0.0013$ ) were independent predictors of APA prescription (Table 4). The estimated effects of such variables on APA prescription were adjusted on all potential confounding covariates included in the model.

\section{Outcome}

The multivariable regression model subsequently revealed that initial invasive mechanical ventilation $(P=0.0076)$ was the only independent predictor of TF (Table 5). The estimated effects of such variables on poor outcomes were adjusted on all potential confounding covariates included in the model.

\section{Nosocomial infections, MDR colonization, and secondary large broad-spectrum antibiotics use}

Twenty-two nosocomial events were recorded: 18 VAP in 47 patients with invasive mechanical ventilation, four urinary tract infections, and two catheter-related infections. Patients receiving APA did not present more nosocomial infections, especially VAP due to MDR bacteria. MDR colonization 
Table I Population characteristics at the time of admission to the intensive care unit

\begin{tabular}{|c|c|}
\hline Population characteristics & $\begin{array}{l}\text { All patients } \\
\text { from January } \\
2000 \text { to } \\
\text { December } \\
2010(n=I I I)\end{array}$ \\
\hline Male, $n(\%)$ & $76(68 \%)$ \\
\hline Age, median (range), years & $72(59-78)$ \\
\hline Tobacco use, n (\%) & 97 (87\%) \\
\hline Body mass index, median (range) & $24.3(20.4-27.1)$ \\
\hline \multicolumn{2}{|l|}{ Comorbidities } \\
\hline Congestive heart failure, $\mathrm{n}(\%)$ & $44(4 \mid \%)$ \\
\hline Arterial hypertension, $\mathrm{n}(\%)$ & 44 (4I\%) \\
\hline Oral steroids before admission, $\mathrm{n}(\%)$ & $30(27 \%)$ \\
\hline FEV, \% of predicted value, median (range) & $36(27.5-47)$ \\
\hline Antibiotics use within 90 previous days, $\mathrm{n}(\%)$ & $51(46 \%)$ \\
\hline Hospitalization $<$ I year, $\mathrm{n}(\%)$ & $44(40 \%)$ \\
\hline Mean delay (months), mean \pm SD & $3 \pm 2$ \\
\hline SAPS II, median (range) & $4 \mathrm{I}(27-50)$ \\
\hline Cardiac rate (pulsation/min), mean \pm SD & $105 \pm 42$ \\
\hline \multicolumn{2}{|l|}{ Arterial blood pressure $(\mathrm{mmHg})$, mean $\pm \mathrm{SD}$} \\
\hline Systolic & $|4| \pm 22$ \\
\hline Diastolic & $73 \pm 15$ \\
\hline Breath rate (respiration/min), mean \pm SD & $29 \pm 11$ \\
\hline $\mathrm{pH}$, mean $\pm \mathrm{SD}$ & $7.22 \pm 0.06$ \\
\hline $\mathrm{pO}_{2}(\mathrm{mmHg})$, mean $\pm \mathrm{SD}$ & $81 \pm 35$ \\
\hline $\mathrm{PCO}_{2}(\mathrm{mmHg})$, mean $\pm \mathrm{SD}$ & $68 \pm 24$ \\
\hline Leukocyte count $(g / L)$, mean \pm SD & $13.9 \pm 6.5$ \\
\hline Noninvasive ventilation, $\mathrm{n}(\%)$ & $52(47 \%)$ \\
\hline Invasive ventilation, $\mathrm{n}(\%)$ & $35(31 \%)$ \\
\hline \multicolumn{2}{|l|}{ Respiratory tract infection diagnosis, $\mathrm{n}(\%)$} \\
\hline Community-acquired (bronchitis/CAP) & $88(79.3 \%)$ \\
\hline Health care associated pneumonia & $9(8.1 \%)$ \\
\hline Bronchitis & $14(12.6 \%)$ \\
\hline Antipseudomonal antibiotics & $48(43 \%)$ \\
\hline PA documented in a respiratory sample & $8(7.2 \%)$ \\
\hline \multicolumn{2}{|l|}{ Prognosis } \\
\hline Secondary need in mechanical ventilation & $12(10.8 \%)$ \\
\hline Secondary need in steroid therapy & $15(13.5 \%)$ \\
\hline Death & $17(15.3 \%)$ \\
\hline
\end{tabular}

Abbreviations: CAP, community-acquired pneumonia; FEV, forced expiratory volume; PA, Pseudomonas aeruginosa; SAPS II, simplified acute physiology score.

and secondary carbapenem use were similar between groups with or without APA prescription.

\section{Discussion}

This study aims to evaluate antibiotics in AECOPD in the ICU. The present study shows a significant rise in APA prescription, since the issue of ATS guidelines about HCAP. Two independent factors influenced prescriptions: the use of invasive mechanical ventilation and the time period following 2006. APA did not improve the prognosis of hospitalized COPD patients.
First, our study outlined that mechanical ventilation influenced APA prescription. Considering the low prevalence of acute respiratory distress syndrome and septic shock in the study population, the use of mechanical ventilation responded mainly to deep alveolar hypoventilation. It has been shown that the prognosis of ventilated patients is determined by organ failure score on admission and comorbidities. ${ }^{18}$ Thus, it seems that there is confusion between respiratory severity and the severity due to sepsis in patients with AECOPD secondary to lower respiratory tract infection. The GOLD guidelines, ${ }^{8}$ advising that antibiotics be given to COPD patients requiring mechanical ventilation only after microbiological sampling, might contribute to this deviation. However, these recommendations do not suggest APA and emphasize that antibiotic choice must be guided by each patient's multidrug-resistant bacteria risk factors. Hence, there is no argument for mechanical ventilation to factor in the choice of an APA. Respiratory severity on admission and PA risk factors should be differentiated.

The notion of a specific timeframe (before and after 2006) also determined antibiotic prescription: the probability of a patient receiving APA was increased sixfold after 2006. A difference in recruitment between the two time periods was suggested to explain this result. However, comparison shows that patients' characteristics were identical, especially as far as PA risk factors are concerned.

Furthermore, our initial hypothesis stated that HCAP diagnosis might have influenced APA prescription. Although no statistical proof exists, APA prescription risk increases fourfold if preceded by HCAP diagnosis. However, the mere $13 \%$ of HCAP diagnosed from 2006 onward cannot account for APA prescription in $53 \%$ of patients during that same time period. This inconsistency supports the hypothesis of an irrational drift in practices.

Our results show that although a majority of patients were sampled, initial APA treatment was not adapted in $>50 \%$ of cases as noted in a previous study..$^{19}$ The overconsumption of large-spectrum antibiotics in ICU patients is not without consequences. Indeed, Aarts et $\mathrm{al}^{20}$ noted a higher mortality rate in patients treated $>4$ days by empirical antibiotics without documented infection. More recently, a study showed a higher mortality rate in ICU patients with HCAP or nosocomial pneumonias treated according to ATS recommendations..$^{21} \mathrm{~A}$ recent study in surgical ICU has shown that a conservative initiation of antimicrobial treatment in critically ill patients did not worsen patient prognosis. ${ }^{22}$

APA was not associated with a better prognosis. This might be due to low PA prevalence on admission (7\%), 
Table 2 Main population characteristics at the admission to the intensive care unit in period $I$ and period 2

\begin{tabular}{|c|c|c|c|c|c|}
\hline & \multicolumn{2}{|c|}{ Period I $(n=48)$} & \multicolumn{2}{|c|}{ Period $2(n=63)$} & \multirow[t]{2}{*}{$P$-value } \\
\hline & Median & IQR & Median & IQR & \\
\hline Age (years) & 71.5 & $57-77$ & 73 & $61-79$ & $0.124^{\#}$ \\
\hline $\begin{array}{l}\text { Body mass index } \\
\left(\mathrm{kg} / \mathrm{m}^{2}\right)\end{array}$ & 25.4 & $20.4-27.5$ & 23.7 & $19-26.3$ & $0.298^{\#}$ \\
\hline FEV (\%) & 35 & $25-46$ & 37 & $30-48$ & $0.384^{\#}$ \\
\hline SAPS II & $\begin{array}{l}37 \\
\text { n (\%) }\end{array}$ & $26-48$ & $\begin{array}{l}43 \\
n(\%)\end{array}$ & $28-53$ & $0.085^{\#}$ \\
\hline \multicolumn{4}{|l|}{ before admission } & & $1.0^{\#}$ \\
\hline \multicolumn{6}{|c|}{ Respiratory tract infection diagnosis, n (\%) } \\
\hline Community acquired & \multicolumn{2}{|c|}{$43(89.6)$} & \multicolumn{2}{|l|}{$45(71.4)$} & $0.016^{\#}$ \\
\hline $\begin{array}{l}\text { Health care } \\
\text { associated }\end{array}$ & \multicolumn{2}{|l|}{$0(0)$} & \multicolumn{2}{|l|}{$9(14.3)$} & \\
\hline Nosocomial & \multicolumn{2}{|l|}{$5(10.4)$} & \multicolumn{2}{|l|}{$9(14.3)$} & \\
\hline $\begin{array}{l}\text { PA in a respiratory } \\
\text { sample }\end{array}$ & \multicolumn{2}{|l|}{$3(6.3)$} & \multicolumn{2}{|l|}{$5(7.9)$} & $1.0^{\#}$ \\
\hline \multicolumn{6}{|c|}{$\begin{array}{l}\text { Type of ventilation administered at the time of admission } \\
\text { to the intensive care unit }\end{array}$} \\
\hline $\begin{array}{l}\text { Spontaneous } \\
\text { breathing }\end{array}$ & \multicolumn{2}{|c|}{$17(35.4)$} & \multicolumn{2}{|c|}{$10(15.9)$} & $0.056 *$ \\
\hline NIV & \multicolumn{2}{|l|}{$17(35.4)$} & \multicolumn{2}{|l|}{$31(49.2)$} & \\
\hline IV & \multicolumn{2}{|l|}{$14(29.2)$} & \multicolumn{2}{|l|}{$22(34.9)$} & \\
\hline \multicolumn{6}{|c|}{ Antibiotic prescription at admission } \\
\hline APA & \multicolumn{2}{|c|}{$10(20.8)$} & \multicolumn{2}{|l|}{$38(60.3)$} & $<0.00 I^{\#}$ \\
\hline Aminosides & \multicolumn{2}{|l|}{$6(12.5)$} & \multicolumn{2}{|l|}{$22(34.9)$} & $0.008^{\#}$ \\
\hline Ureidopenicillin & \multicolumn{2}{|l|}{$5(10.4)$} & \multicolumn{2}{|l|}{$30(47.6)$} & $<0.00 l^{\#}$ \\
\hline Ceftazidime & \multicolumn{2}{|l|}{$3(6.3)$} & \multicolumn{2}{|l|}{$0(0)$} & $0.078^{\#}$ \\
\hline Carbapenems & $0(0)$ & & $2(3.2)$ & & $0.505^{\#}$ \\
\hline Ciprofloxacin & $4(8.3)$ & & $16(25.4)$ & & $0.025^{\#}$ \\
\hline Antibiotic adaptation & $4(8.3)$ & & $14(22.2)$ & & $0.068^{\#}$ \\
\hline $\begin{array}{l}\text { Carbapenem } \\
\text { prescription }\end{array}$ & $0(0)$ & & $2(3)$ & & 0.51 \\
\hline $\begin{array}{l}\text { MDR bacteria } \\
\text { colonization } \\
\text { Outcome }\end{array}$ & $6(13)$ & & $7(11)$ & & 1.0 \\
\hline $\begin{array}{l}\text { Secondary need } \\
\text { in MV }\end{array}$ & $5(10)$ & & $7(11)$ & & 1.00 \\
\hline $\begin{array}{l}\text { Secondary need } \\
\text { in steroids }\end{array}$ & $4(8)$ & & II (I8) & & 0.21 \\
\hline Death & $9(19)$ & & $8(13)$ & & 0.43 \\
\hline Treatment failure & $14(29)$ & & $20(32)$ & & 0.84 \\
\hline
\end{tabular}

Notes: "Mann-Whitney U-test, * $\chi^{2}$ test.

Abbreviations: APA, antipseudomonal antibiotics; FEV, forced expiratory volume; IQR, interquartile range; IV, invasive ventilation; MV, mechanical ventilation; NIV, noninvasive ventilation; PA, Pseudomonas aeruginosa; SAPS II, simplified acute physiology score.

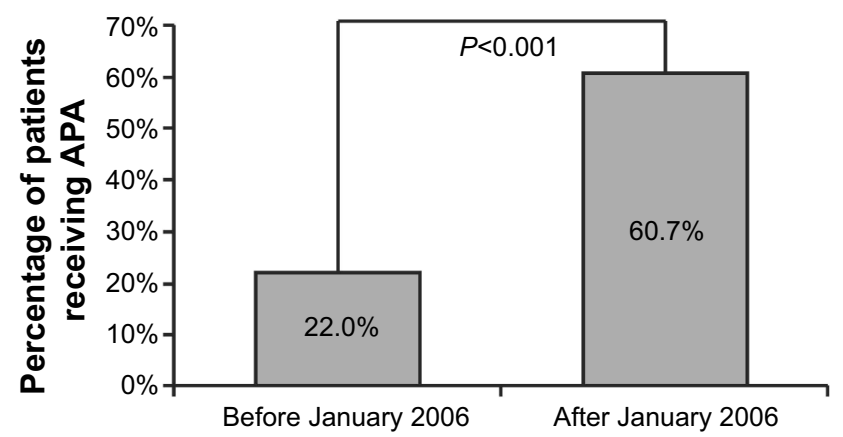

Figure 2 Antipseudomonal antibiotics (APA) prescription frequency prior to and after January 2006.

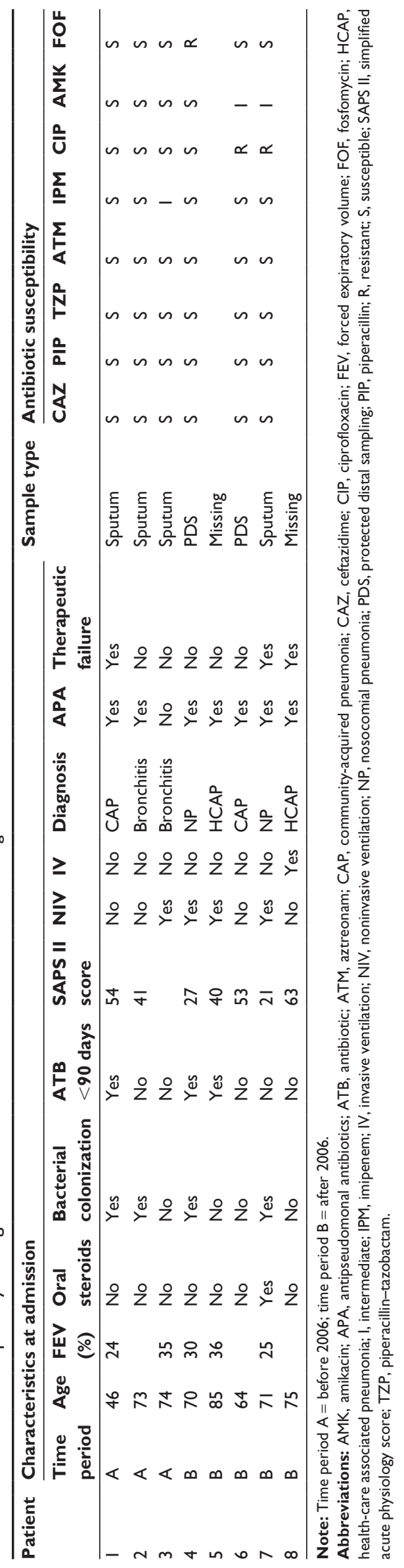




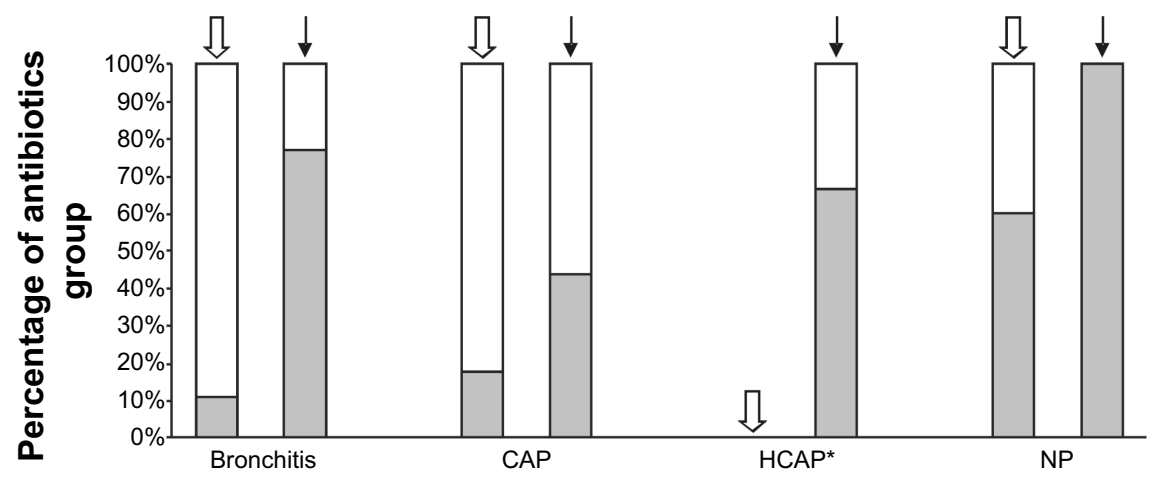

Figure 3 Antibiotic prescription depending on the respiratory infection diagnosis (bronchitis, CAP, HCAP, or NP).

Notes: *HCAP diagnosis was used as of January I, 2006. White: antibiotics inactive on Pseudomonas aeruginosa, grey: antibiotics active on Pseudomonas aeruginosa. Before 2006 (thick arrow); after 2006 (thin arrow).

Abbreviations: CAP, community-acquired pneumonia; HCAP, health care-associated pneumonia; NP, nosocomial pneumonia.

Table 4 Predictive factors of PA antibiotherapy use

\begin{tabular}{|c|c|c|c|c|c|c|}
\hline $\begin{array}{l}\text { Patient } \\
\text { characteristics }\end{array}$ & N (\%) & APA (\%) & $\begin{array}{l}\text { Univariate OR } \\
(95 \% \mathrm{Cl})\end{array}$ & $\begin{array}{l}\text { Univariate } \\
P \text {-value* }\end{array}$ & $\begin{array}{l}\text { Multivariate OR } \\
(95 \% \mathrm{CI})\end{array}$ & $\begin{array}{l}\text { Multivariate } \\
P \text {-value }\end{array}$ \\
\hline \multicolumn{7}{|l|}{ Sex } \\
\hline Male & $76(69)$ & 42 & 0.86 (NA) & 0.72 & $\mathrm{NI}$ & \\
\hline Female & $35(31)$ & 46 & REF & & & \\
\hline \multicolumn{7}{|l|}{ Age (years) } \\
\hline$<65$ & $40(36)$ & 43 & REF & 0.91 & $\mathrm{NI}$ & \\
\hline$>65$ & 7I (64) & 44 & $1.05(0.48-2.29)$ & & & \\
\hline \multicolumn{7}{|l|}{ BMI $\left(\mathrm{kg} / \mathrm{m}^{2}\right)$} \\
\hline$<18.5$ & $12(15)$ & 33 & REF & 0.439 & REF & 0.45 \\
\hline$\geq 18.5$ & $66(85)$ & 46 & $1.67(0.46-6.08)$ & & $2.28(0.27-19.24)$ & \\
\hline \multicolumn{7}{|c|}{ Comorbidities (congestive heart failure or chronic renal failure) } \\
\hline Yes & $49(44)$ & 43 & $0.97(0.46-2.07)$ & 0.94 & $\mathrm{NI}$ & \\
\hline No & $62(56)$ & 44 & REF & & & \\
\hline \multicolumn{7}{|l|}{ FEV (\%) } \\
\hline$<40$ & $53(64)$ & 43 & REF & 0.77 & REF & 0.91 \\
\hline$>40$ & $30(36)$ & 47 & $1.14(0.46-2.8 I)$ & & $1.07(0.35-3.32)$ & \\
\hline \multicolumn{7}{|l|}{ Oral steroids at admission } \\
\hline Yes & $30(27)$ & 53 & I.7I (0.74-3.99) & 0.21 & $1.61(0.50-5.19)$ & 0.42 \\
\hline No & $80(73)$ & 40 & REF & & REF & \\
\hline \multicolumn{7}{|l|}{ PA in respiratory sample } \\
\hline Yes & $13(12)$ & 69 & $3.49(1.00-12.15)$ & 0.040 & $2.76(0.50-15.53)$ & 0.24 \\
\hline No & $97(88)$ & 39 & REF & & REF & \\
\hline \multicolumn{7}{|l|}{ Respiratory tract infection } \\
\hline Community acquired & $88(79)$ & 35 & REF & 0.0030 & REF & 0.088 \\
\hline Health care associated & $9(8)$ & 67 & $3.68(0.86-15.73)$ & & $4.16(0.36-48.70)$ & \\
\hline Nosocomial & $14(13)$ & 79 & $6.74(1.75-25.99)$ & & $4.20(0.90-19.54)$ & \\
\hline \multicolumn{7}{|l|}{ SAPS II } \\
\hline$<50$ & 79 (7I) & 44 & REF & 0.72 & REF & 0.49 \\
\hline$>50$ & $32(29)$ & I & $0.86(0.37-1.98)$ & & $0.64(0.18-2.25)$ & \\
\hline \multicolumn{7}{|c|}{ Type of ventilation administered at the time of admission to the intensive care unit } \\
\hline Spontaneous breathing & $27(24)$ & 33 & REF & 0.17 & REF & 0.03 \\
\hline NIV & $48(43)$ & 40 & $1.31(0.49-3.52)$ & & $1.05(0.24-4.62)$ & \\
\hline IV & $36(32)$ & 56 & $2.5(0.89-7.04)$ & & $4.86(1.01-23.38)$ & \\
\hline \multicolumn{7}{|l|}{ Time period } \\
\hline Before 2006 & $48(43)$ & 21 & REF & & REF & \\
\hline After 2006 & $63(57)$ & 60 & $5.78(2.44-13.65)$ & $<0.001$ & 6.21 (1.89-20.35) & 0.0013 \\
\hline
\end{tabular}

Notes: * $\chi^{2}$ test was used to compare proportions. ${ }^{\dagger}$ Mann-Whitney $U$-test and Kruskall-Wallis test were used (if we compare ordinal or continuous variables). $\neq$ Likelihoodratio test.

Abbreviations: APA, antipseudomonal antibiotics; BMI, body mass index; Cl, confidence interval; FEV, forced expiratory volume; IV, invasive ventilation; NI, not included; NIV, noninvasive ventilation; OR, odds ratio; PA, Pseudomonas aeruginosa; REF, reference; SAPS II, simplified acute physiology score. 
Table 5 Predictive factors of the composite endpoint (death + ventilation + oral steroids)

\begin{tabular}{|c|c|c|c|c|c|c|}
\hline $\begin{array}{l}\text { Patient } \\
\text { characteristics }\end{array}$ & $\mathbf{N}(\%)$ & Outcome (\%) & $\begin{array}{l}\text { Univariate OR } \\
(95 \% \mathrm{Cl})\end{array}$ & $\begin{array}{l}\text { Univariate } \\
P \text {-value }\end{array}$ & $\begin{array}{l}\text { Multivariate OR } \\
(95 \% \mathrm{CI})\end{array}$ & $\begin{array}{l}\text { Multivariate } \\
\text { P-value }\end{array}$ \\
\hline \multicolumn{7}{|l|}{ Age (years) } \\
\hline$<65$ & $40(36)$ & 20 & REF & & REF & \\
\hline$>65$ & $71(64)$ & 37 & $2.31(0.93-5.76)$ & 0.068 & $1.89(0.59-6.08)$ & 0.29 \\
\hline \multicolumn{7}{|l|}{ FEV (\%) } \\
\hline$<30$ & $24(29)$ & 38 & REF & & REF & \\
\hline $30-50$ & $48(58)$ & 25 & $0.56(0.19-1.59)$ & & $0.54(0.13-2.12)$ & \\
\hline $50-70$ & $10(12)$ & 20 & $0.42(0.072-2.4 \mathrm{I})$ & & $0.22(0.02-2.26)$ & \\
\hline$>70$ & $I(I)$ & 100 & NA & 0.255 & - & 0.51 \\
\hline \multicolumn{7}{|l|}{ Oral steroids at admission } \\
\hline Yes & $30(27)$ & 23 & $0.60(0.23-1.57)$ & & $0.81(0.25-2.62)$ & \\
\hline No & $80(73)$ & 34 & REF & 0.29 & REF & 0.72 \\
\hline \multicolumn{7}{|l|}{ BMI $\left(\mathrm{kg} / \mathrm{m}^{2}\right)$} \\
\hline$<18.5$ & $12(15)$ & 42 & REF & & REF & \\
\hline$\geq 18.5$ & $66(85)$ & 35 & $0.75(0.2 \mathrm{I}-2.63)$ & 0.16 & $0.32(0.06-1.65)$ & 0.17 \\
\hline \multicolumn{7}{|l|}{ PA treatment } \\
\hline Yes & $48(43)$ & 35 & $1.48(0.66-3.34)$ & & $1.09(0.37-3.23)$ & \\
\hline No & $63(57)$ & 27 & REF & 0.34 & REF & 0.88 \\
\hline \multicolumn{7}{|l|}{ PA in respiratory sample } \\
\hline Yes & $13(12)$ & 15 & $0.37(0.077-1.77)$ & & $0.32(0.05-2.27)$ & \\
\hline No & $97(88)$ & 33 & REF & 0.20 & REF & 0.25 \\
\hline \multicolumn{7}{|c|}{ Colonization (nasal MRSA + enterobacteria + pulmonary MRSA) } \\
\hline Yes & $13(12)$ & 46 & $2.14(0.66-6.94)$ & & $0.75(0.19-3.02)$ & \\
\hline No & $98(88)$ & 29 & REF & 0.20 & REF & 0.69 \\
\hline \multicolumn{7}{|c|}{ Respiratory tract infection diagnosis } \\
\hline Community acquired & $88(79)$ & 26 & REF & & REF & \\
\hline Health care associated & $9(8)$ & 56 & $3.53(0.87-14.30)$ & & $3.24(0.60-17.65)$ & \\
\hline Nosocomial & $14(13)$ & 43 & $2.12(0.66-6.76)$ & 0.108 & $3.11(0.62-15.63)$ & 0.20 \\
\hline \multicolumn{7}{|l|}{ SAPS II } \\
\hline$<50$ & $79(7 I)$ & 25 & REF & & REF & \\
\hline$>50$ & $32(29)$ & 44 & $2.29(0.97-5.44)$ & 0.056 & $1.95(0.62-6.15)$ & 0.25 \\
\hline \multicolumn{7}{|c|}{ Type of ventilation administered at the time of admission to the intensive care unit } \\
\hline Spontaneous breathing & $27(24)$ & 11 & REF & & REF & \\
\hline NIV & $48(43)$ & 27 & $2.97(0.76-11.56)$ & & $3.43(0.68-17.27)$ & \\
\hline IV & $36(32)$ & 50 & $8.00(2.04-31.37)$ & 0.003 & 10.88 (1.97-60.09) & 0.0076 \\
\hline
\end{tabular}

Abbreviations: BMI, body mass index; $\mathrm{Cl}$, confidence interval; FEV, forced expiratory volume; ICU, intensive care unit; IV, invasive ventilation; NIV, noninvasive ventilation; OR, odds ratio; PA, Pseudomonas aeruginosa; REF, reference; SAPS II, simplified acute physiology score.

similar to that of other studies. A positive PA respiratory sample does not systematically demonstrate PA respiratory tract infection. The wild strain of isolated PA, all sensitive to prescribed APA in the present study, could also have positively influenced the patient's prognosis. Aloush et $\mathrm{a}^{23}$ showed that multi resistant-PA was associated with an increase of hospital stay and of staff workload and with a tainted quality of life. A meta-analysis confirmed the impact of Gram-negative bacterial resistance on ICU outcome. ${ }^{24} \mathrm{~A}$ recent study showed that VAP caused by multidrug-resistant PA were associated with a prolonged ICU stay. ${ }^{25}$

Practitioners' difficulty to differentiate active infection from bacterial colonization reveals the complexity of lower respiratory tract infection diagnosis in AECOPD. These obstacles to diagnosis might lead to an irrational overprotective approach and antibiotic overprescription. Written guidelines identifying high-risk patients for PA would help in introducing broad-spectrum antibiotics for ICU patients after respiratory sampling and in reducing antibiotics spectrum in the absence of PA.

This study presents some limits. As this is a retrospective design, missing data are inevitable. However, it consists, in this particular case, mainly of demographic factors. The results of 107 samples were analyzed, and we were always able to retrieve the data that define our "composite endpoint". Therapeutic failure was defined by a composite endpoint rather than a raw mortality rate, which would not have been powerful enough. Indeed, global mortality reached $15 \%$ in our series. This endpoint also allowed us to take into account the failure of a first line of treatment, of which antibiotherapy is considered 
a major element. Multiple covariates were included in multivariate models, and no covariate selection was performed because it was deemed desirable to include as many factors associated with outcomes (APA prescription and TF) as possible. The effect size of covariates statistically significantly associated with outcomes was stable through all sensitivity analysis (univariate models and multivariate models operating covariate selection). ${ }^{26}$ Finally, our conclusions are limited by the small number of PA-positive patients $(n=8)$.

\section{Conclusion}

Our results show a significant increase in APA prescription in patients admitted in ICU for AECOPD starting from 2006, without better prognosis and that APA prescription was associated with the use of mechanical ventilation and the time period following 2006, probably revealing the confusion between ATS guidelines, PA risk factors in COPD patients, and the severity of respiratory distress. Considering the high prevalence of MDR bacteria in ICUs, these results are concerning and incite us to greater caution with the consumption of broad-spectrum antibiotics. Meanwhile, a larger multicentric study is needed to confirm our findings and to evaluate the impact on bacterial ecology and broad-spectrum antibiotic consumption during nosocomial infections.

\section{Disclosure}

The authors report no conflicts of interest in this work.

\section{References}

1. Ai-Ping C, Lee K-H, Lim TK. In-hospital and 5-year mortality of patients treated in the ICU for acute exacerbation of COPD: a retrospective study. Chest. 2005;128(2):518-524.

2. Seneff MG, Wagner DP, Wagner RP, Zimmerman JE, Knaus WA. Hospital and 1-year survival of patients admitted to intensive care units with acute exacerbation of chronic obstructive pulmonary disease. JAMA. 1995;274(23):1852-1857.

3. Hurst JR, Vestbo J, Anzueto A, et al. Susceptibility to exacerbation in chronic obstructive pulmonary disease. N Engl J Med. 2010;363(12):1128-1138.

4. Soler-Cataluña JJ, Martínez-García MA, Román Sánchez P, Salcedo E, Navarro M, Ochando R. Severe acute exacerbations and mortality in patients with chronic obstructive pulmonary disease. Thorax. 2005;60(11):925-931.

5. Seemungal TA, Donaldson GC, Paul EA, Bestall JC, Jeffries DJ, Wedzicha JA. Effect of exacerbation on quality of life in patients with chronic obstructive pulmonary disease. Am J Respir Crit Care Med. 1998;157(5 pt 1):1418-1422.

6. Papi A, Bellettato CM, Braccioni F, et al. Infections and airway inflammation in chronic obstructive pulmonary disease severe exacerbations. Am J Respir Crit Care Med. 2006;173(10):1114-1121.

7. Sethi S, Evans N, Grant BJB, Murphy TF. New strains of bacteria and exacerbations of chronic obstructive pulmonary disease. $N$ Engl J Med. 2002;347(7):465-471.

8. Vestbo J, Hurd SS, Agustí AG, et al. Global strategy for the diagnosis, management, and prevention of chronic obstructive pulmonary disease: GOLD executive summary. Am J Respir Crit Care Med. 2013;187(4):347-365.
9. Monsó E, Ruiz J, Rosell A, et al. Bacterial infection in chronic obstructive pulmonary disease. A study of stable and exacerbated outpatients using the protected specimen brush. Am J Respir Crit Care Med. 1995;152(4 pt 1):1316-1320.

10. Nouira S, Marghli S, Belghith M, Besbes L, Elatrous S, Abroug F. Once daily oral ofloxacin in chronic obstructive pulmonary disease exacerbation requiring mechanical ventilation: a randomised placebocontrolled trial. Lancet. 2001;358(9298):2020-2025.

11. Murphy TF, Brauer AL, Eschberger K, et al. Pseudomonas aeruginosa in chronic obstructive pulmonary disease. Am J Respir Crit Care Med. 2008;177(8):853-860.

12. Lode $\mathrm{H}$, Allewelt $\mathrm{M}, \mathrm{Balk} \mathrm{S}$, et al. A prediction model for bacterial etiology in acute exacerbations of COPD. Infection. 2007;35(3): 143-149.

13. Garcia-Vidal C, Almagro P, Romaní V, et al. Pseudomonas aeruginosa in patients hospitalised for COPD exacerbation: a prospective study. Eur Respir J. 2009;34(5):1072-1078.

14. Kollef MH, Morrow LE, Niederman MS, et al. Clinical characteristics and treatment patterns among patients with ventilator-associated pneumonia. Chest. 2006;129(5):1210-1218.

15. American Thoracic Society, Infectious Diseases Society of America. Guidelines for the management of adults with hospital-acquired, ventilator-associated, and healthcare-associated pneumonia. $\mathrm{Am} \mathrm{J}$ Respir Crit Care Med. 2005;171(4):388-416.

16. Nseir S, Ader F, Lubret R, Marquette CH. Pathophysiology of airway colonization in critically ill COPD patient. Curr Drug Targets. 2011;12(4):514-520.

17. Wilson R, Anzueto A, Miravitlles M, et al. A novel study design for antibiotic trials in acute exacerbations of COPD: MAESTRAL methodology. Int J Chron Obstruct Pulmon Dis. 2011;6:373-383.

18. Nevins ML, Epstein SK. Predictors of outcome for patients with COPD requiring invasive mechanical ventilation. Chest. 2001;119(6): $1840-1849$

19. Kollef MH, Shorr A, Tabak YP, Gupta V, Liu LZ, Johannes RS. Epidemiology and outcomes of health-care-associated pneumonia: results from a large US database of culture-positive pneumonia. Chest. 2005;128(6):3854-3862.

20. Aarts MA, Brun-Buisson C, Cook DJ, et al. Antibiotic management of suspected nosocomial ICU-acquired infection: does prolonged empiric therapy improve outcome? Intensive Care Med. 2007;33(8):1369-1378.

21. Kett DH, Cano E, Quartin AA, et al. Implementation of guidelines for management of possible multidrug-resistant pneumonia in intensive care: an observational, multicentre cohort study. Lancet Infect Dis. 2011; 11(3):181-189.

22. Hranjec T, Rosenberger LH, Swenson B, et al. Aggressive versus conservative initiation of antimicrobial treatment in critically ill surgical patients with suspected intensive-care-unit-acquired infection: a quasi-experimental, before and after observational cohort study. Lancet Infect Dis. 2012;12(10):774-780.

23. Aloush V, Navon-Venezia S, Seigman-Igra Y, Cabili S, Carmeli Y. Multidrug-resistant Pseudomonas aeruginosa: risk factors and clinical impact. Antimicrob Agents Chemother. 2006;50(1):43-48.

24. Shorr AF. Review of studies of the impact on Gram-negative bacterial resistance on outcomes in the intensive care unit. Crit Care Med. 2009;37(4):1463-1469.

25. Planquette B, Timsit J-F, Misset BY, et al; OUTCOMEREA Study Group. Pseudomonas aeruginosa ventilator-associated pneumonia Predictive factors of treatment failure. Am J Respir Crit Care Med. 2013;188(1):69-76.

26. Concato J, Feinstein AR, Holford TR. The risk of determining risk with multivariable models. Ann Intern Med. 1993;118(3):201-210. 


\section{Publish your work in this journal}

The International Journal of COPD is an international, peer-reviewed journal of therapeutics and pharmacology focusing on concise rapid reporting of clinical studies and reviews in COPD. Special focus is given to the pathophysiological processes underlying the disease, intervention programs, patient focused education, and self management protocols.

This journal is indexed on PubMed Central, MedLine and CAS. The manuscript management system is completely online and includes a very quick and fair peer-review system, which is all easy to use. Visit http://www.dovepress.com/testimonials.php to read real quotes from published authors.

Submit your manuscript here: http://www.dovepress.com/international-journal-of-chronic-obstructive-pulmonary-disease-journal 